Surgery was considered on days two and six. The knee-elbow position reversed the radiographic appearances, however, and changed the treatment of our patient's colitis. The use of this simple and safe manoeuvre probably spared our patient from surgical intervention.

\section{J FLETCHER}

A J LOBO

R F HARVEY

Frenchay Hospital,

Bristol BS16 1LE

EDIToR,-Panos et al (Gut 1993; 34: 1726-7) describe the knee-elbow position for the relief of bowel distension in patients with toxic megacolon. They suggest that their use of this therapeutic manoeuvre is new.

In 1988 Present et al ${ }^{1}$ published their experience with 'rolling' 19 patients with toxic megacolon into the prone position every two to three hours for 10 to 15 minutes. They concluded this was a helpful addition to the standard treatment for this serious condition.

Both groups are describing the same phenomenon - the prone position redistributes colonic gas and fluid into the lower bowe leading to easier evacuation. We have been using this technique for several years at the Stanford Medical Center.

R R BABB

Palo Alto Medical Clinic, 300 Homer Ave, Palo Alto,

CA 94301, USA

1 Present DH, Wolfson D, Gelernt IM, Rubin PH, Bauer J, Chapman ML. Medical decompression of toxic megacolon by 'rolling'. A new technique of decompression with favourable long-term follow-up. $¥$ Clin Gastroenterol 1988; 10: $485-90$.

Reply

We welcome the correspondence on our case report, which gives us the opportunity of further discussion of the use of postural manoeuvres for bowel decompression 'Rolling', as described by Dr Present et al, entails turning the patient to the prone position, on a flat bed. ${ }^{1}$ This position is clearly different from the knee-elbow position we have reported in which the patient is positioned head down with hips, knees, and elbows flexed. ${ }^{2}$

A crucial point needs to be made with respect to the 'rolling' regimen, as described by Present $e t$ al in their series of 19 patients: in addition to turning the patient prone, a long enteral tube was passed for aspiration of gas and enteral fluid. ${ }^{1}$ Consequently it is difficult to discern what the individual contribution of the intubation-aspiration versus the postural manoeuvre was, in decompressing the bowel We also note that in five of their 19 cases, a rectal catheter was required to facilitate evacuation of gas that had not been forthcoming. ${ }^{1}$ The uppermost position of the rectum and anus in the knee-elbow position permits easy passage of flatus and could obviate the need for rectal catheterisation.

The early and longterm follow up results from Dr Present's uncontrolled series are impressive. Nevertheless, the effect of bowel decompression by postural manoeuvres on the outcome of toxic megacolon should be confirmed by prospective, randomised, controlled trials.

We remain unaware of any previous reports of the use of the knee-elbow position to decompress the bowel in toxic megacolon.

M Z PANOS $M J$ WOOD $P$ ASQUITH Department of Medicine,

University of Birmingham Medical School and East
Birmingham Hospital,
Birmingham

University of Birmingham Medical School and East
Birmingham Hospital,
Birmingham

1 Present DH, Wolfson D, Gelernt IM, Rubin PH, Bauer J, Chapman ML. Medical decompression of toxic megacolon by rolling. A new technique of decompression with favourable technique of decompression with favourable long-term foll

2 Hamilton Bailey. Physical signs in clinical surgery. 11th Ed. Bristol: J Wright, 1949: 229.

\section{Acid and gastric metaplasia in the} duodenum

EDITOR,-We read with great interest the paper by Noach et al (Gut 1993; 34: 1510-4) on the relation between duodenal gastric metaplasia and Helicobacter pylori infection. Two findings deserve particular attention in this study. Firstly, the presence and extent of gastric metaplasia in the duodenum was not significantly associated with $H$ pylori infection, because it was found in $78 \%$ of $H$ pylori positive and in $85 \%$ of $H$ pylori negative patients with dyspeptic complaints. Secondly, there was no reduction in the extent and prevalence of gastric metaplasia after 12 months of eradication of $\mathrm{H}$ pylori.

The first finding obviously excludes the responsibility of $H$ pylori in the formation of gastric metaplasia in the duodenum, but raises serious questions on the role of acid in this process. ${ }^{1}$ In fact, a study has already shown that patients with functional dyspepsia have a basal acid output that is comparable with that of normal subjects. ${ }^{2}$ Using ambulatory $\mathrm{pHmetry}^{3}$ we have even found that the circadian gastric acidity in $H$ pylori negative dyspeptic patients is significantly lower (24 hour mean (SEM) pH $2.8(0.8)$ v $1.8(0.4)$, $\mathrm{p}<0.001$ ) than normal (Figure). In addition, although $H$ pylori infection results in an increase in gastrin release, this hypergastrinaemia does not induce an increase in acid secretion. There is no difference, indeed, in basal and maximal acid output ${ }^{4}$ and in 24 hour intragastric acidity ${ }^{5}$ between $H$ pylori positive and negative patients. Finally, it is well known that only some patients with duodenal ulcer disease secrete an amount of gastric acid higher than normal ${ }^{6}$ and only a subgroup of them shows a rapid gastric emptying, ${ }^{7}$ which could result in an increased

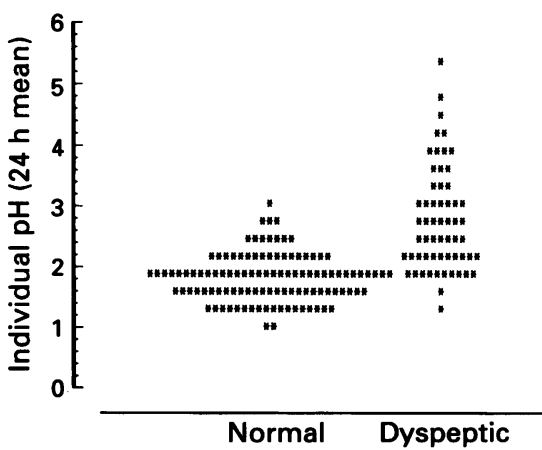

Distribution of individual pH (24h mean) in normal subjects and patients with functional dyspepsia. Recordings made for the 24 hour period from 1700 to 1659. acid load to the duodenum with subsequent mucosal injury.

On the basis of these findings, the common belief that gastric metaplasia in the duodenum is induced by hypersecretion of gastric acid $^{89}$ is questionable.

The finding of the lack of regression of gastric metaplasia in the bulb after 12 months of eradication of $H$ pylori has been explained by the authors by the fact that gastric acid secretion is not changed by treatment of the infection $^{10}$ and therefore, the persistent high production of acid helps to maintain the histological duodenal alteration. As acid hypersecretion is not the rule in duodenal ulcer, however, and is not present in functional dyspepsia, it is again difficult to claim this physiological abnormality as the main cause of maintenance of gastric metaplasia in the long term.

Thus, it seems that the presence of $H$ pylori, by itself, is the main factor in the development of duodenal ulcer, although the mechanisms of this action are far from clear. As suggested by the authors, the mucosal production of cytokines and specific toxins released by the bacterium might be possible ulcerogenetic factors, independent of gastric metaplasia. The persistence of this epithelial change in patients where $H$ pylori has been eradicated who show a dramatic reduction in ulcer relapse, seems to diminish further its pathogenetic relevance.

$$
\begin{array}{r}
\text { V SAVARINO } \\
\text { G MELA } \\
\text { G CELLE } \\
\text { Department of Internal Medicine, } \\
\text { University of Genova, Italy } \\
\text { S VIGNERI } \\
\text { Institute of Internal Medicine and Geriatrics, } \\
\text { University of Palermo, Italy }
\end{array}
$$

1 Wyatt JI, Rathbone BJ, Dixon MF, Heatley RV, Axon ATR. Campylobacter pylori and development of duodenal ulcer [Letter]. Lancet 1988; i: 118-9.

2 Collen MJ. Gastric analysis (basal acid output) in nonulcer dyspepsia. Dig Dis Sci 1990; 35: $540-1$

3 Savarino V, Mela GS, Zentilin P, Magnolia MR, Scalabrini $P$, Valle $F$, et al. Gastric aspiration versus antimony and glass electrodes. A simulversus antimony and glass electrodes. A simulGastroenterol 1989; 24: 434-9.

4 Brady III CE, Hadfield TL, Hyatt JR, Utts SJ. Acid secretion and serum gastrin levels in individuals with Campylobacter pylori. Gastroenterology 1988; 94: 923-7.

5 Wagner S, Gladziwa U, Haruma K, Varrentrapp M, Gebel M. Effect of Helicobacter pylori infection on 24 hour intragastric acidity in patients with gastritis and duodenal ulcer. Gut 1992; 33: 1024-7.

6 Baron $\mathrm{JH}$. The relationship between basal and maximum acid output in normal subjects and patients with duodenal ulcer. Clin Sci 1963; 24: 357-70.

7 Lam SK. Pathogenesis and pathophysiology of duodenal ulcer. Clin Gastroenterol 1984; 13: 447-72.

8 Wyatt II, Rathbone BJ, Dixon MF, Heatley RV. Campylobacter pyloridis and acid-induced gastric metaplasia in the pathogenesis of duodenitis. F Clin Pathol 1987; 40: 841-8.

9 Carrick J, Lee A, Hazell S, Ralston M, Daskalopoulos G. Campylobacter pylori, duodenal ulcer, and gastric metaplasia: possible role of functional heterotopic tissue in ulcerogenesis. Gut 1989; 30: 790-7.

10 Montbriand JR, Appelman HD, Cotner EK, Nostrant TT, Elta GH. Treatment of Campylobacter pylori does not alter gastric acid secretion. Am $\mathcal{F}$ Gastroenterol 1989; 84: 1513-6.

\section{Reply}

EDITOR,-We thank Savarino et al for their interest in our study on Helicobacter pylori and gastric metaplasia in the duodenum. 